\title{
Identification of operational performance attributes for pasture measuring devices
}

C.R. EASTWOOD and B.T. DELA RUE

\section{Abstract}

Farmers have expressed difficulty determining the performance of precision farming devices both before and after purchase. The aim of this study was to develop guidelines for operational performance of pasture measuring devices using a Delphi survey method with 25 dairy pasture management specialists. The eight important attributes of devices for use on dairy farms, as identified by survey respondents were: the device is easy to use; weekly data are available during high pasture growth periods; data are available within 24 hours of measurement; data are accurate; data are collected quickly; data are easily uploaded into third party software; the device is easy to maintain; and the device has been/can be calibrated for ryegrass/ clover swards. The attributes identified through this process provide measurement device developers with a design guide. The results also provide farmers with a list of attributes to consider when investing in pasture measuring devices or services.

Keywords: pasture measurement, technology development, precision grazing, Delphi survey

\section{Introduction}

Regular measurement of pasture biomass provides important information for making decisions about pasture allocation for dairy herds, meeting growth rate and production targets, and annual performance of paddocks (McCarthy et al. 2014). Measuring pasture using a tool is time consuming and creates conflicts in priority for farmers as the key period for measurement (spring) coincides with many other important farm tasks around calving and mating (Eastwood et al. 2017). Visual assessment is a rapid method of gathering data but requires considerable experience and occasional cross-checking or calibration to maintain accuracy. It can be difficult for inexperienced staff (and even for

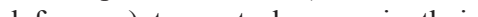
estimates.

For farmers wanting to standardise their pasture assessment, there are several commercially-available pasture measuring tools with the most common being the Rising Plate Meter (Thomson et al. 2001) followed by the Rapid Pasture Meter ${ }^{\mathrm{TM}}$ by C-Dax (King et al. 2010). Other tools include the Sward Stick, Automatic Pasture Reader (Ballance Agri-Nutrients Ltd), Rapid
Plate Meter and Pasture Probe (Jenquip NZ Inc). In the fevers available on platforms on such as satellites, fixed wing aircraft, and unmanned aerial vehicles (Pullanagari et al. 2011) Studies on adoption of precision dairy technologies have highlighted a range in on-farm performance and value for farmers (Edwards et al. 2015; Eastwood et al. 2016; Dela Rue \& Eastwood 2017). Also, farmers often have difficulty determining the performance of devices before and evaluating after purchase. It is, therefore, important to understand the performance attributes the pefortes pertify mportan optaton for pasture measuring technologies, aimed at improving understanding by technology developers of operational attributes required by farmers, and to provide farmers with a framework to make informed purchases.

\section{Methods}

A two-stage Delphi survey (Hasson \& Keeney 2011) was developed to examine the views of grazing management and measurement specialists on the basic expectations for operational performance of pasture measuring devices in dairy farm decision making. An initial list of attributes for pasture measurement was identified from previous studies (Dalley et al. 2009; Eastwood \& Kenny 2009; Eastwood et al. 2017). A pilot survey was conducted in February 2017 with five farm systems specialists within DairyNZ Ltd, and their feedback was used to refine the survey questions. The draft attribute list was then presented to a group of draft attribute list was then presen
specialists in a two-stage survey.

Twenty-five experts were selected from professiona networks, and the respondents (with the number of respondents for Survey 1 and Survey 2, respectively, in brackets) were from New Zealand $(16,13)$, Ireland $(5,4)$, Australia $(3,3)$ and Scotland $(1,0)$. The roles of respondents included researchers $(14,11)$, technology developers $(4,6)$, farmer $(1,1)$, and service providers (6) $(6,2)$. or others $(6,2)$, in total the were 25 respents to Survey 1 and 20 respondents to Survey 2. All were considered to have extensive experience in pasture management and in the development or use of measuring tools, with $60 \%$ of respondents stating they had more than 20 years of experience in pasture management, $27 \%$ having $11-20$ years, and $13 \%$ having less than 10 years. 
Survey 1: A draft list of attributes was presented to survey participants using the SurveyMonkey ${ }^{\mathrm{TM}}$ online platform (for Survey 1 and 2). Participants were asked to rate each attribute as 'Very important', 'Important', 'Somewhat important', 'Not important', or 'Undecided'. Some of the attributes, highlighted in Table 1, were related to devices that farmers would operate themselves (for example 'easy to use', and not satellite and/or subscription services). Results from the first survey were analysed and the attributes ranked from most to least important overall.

Survey 2: Respondents were asked to review the ranked list and re-order the attributes if they did not agree with the collective rankings. Respondents were also asked to indicate the importance of each attribute by selecting it as 'need to have' and 'nice to have' or 'not required' for pasture measurement. Survey
Table 1 Ranking of pasture measurement technology attributes based on responses from a Delphi survey with 25 pasture management specialists (S1 = Survey 1, S2 = Survey 2).

\begin{tabular}{|c|c|c|c|c|c|c|c|c|c|c|}
\hline & \multicolumn{5}{|c|}{ S1 results (\%) } & \multicolumn{3}{|c|}{ Attribute rankings } & \multicolumn{2}{|c|}{$\begin{array}{l}\text { Need for attribute } \\
\text { in device (S2) }\end{array}$} \\
\hline & 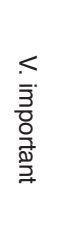 & 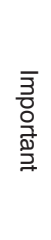 & 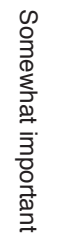 & 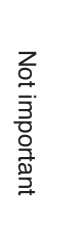 & 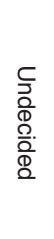 & 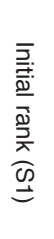 & 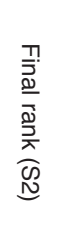 & 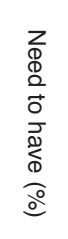 & 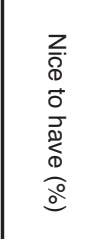 & 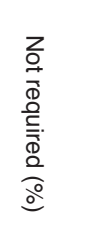 \\
\hline \multicolumn{11}{|l|}{ 'NEED TO HAVE' } \\
\hline $\begin{array}{l}\text { For farmer operated devices, } \\
\text { the device is easy to use }\end{array}$ & 76 & 20 & 4 & 0 & 0 & 1 & 1 & 89 & 11 & 0 \\
\hline $\begin{array}{l}\text { Pasture data available weekly } \\
\text { during high growth periods }\end{array}$ & 75 & 21 & 4 & 0 & 0 & 2 & 2 & 90 & 10 & 0 \\
\hline $\begin{array}{l}\text { Pasture data available for farmers } \\
\text { within } 24 \text { hours of measuring }\end{array}$ & 71 & 25 & 4 & 0 & 0 & 3 & 3 & 80 & 20 & 0 \\
\hline $\begin{array}{l}\text { The pasture data are accurate } \\
\text { (e.g. }+/-200 \mathrm{~kg} \mathrm{DM} / \mathrm{ha})\end{array}$ & 36 & 52 & 12 & 0 & 0 & 7 & 4 & 84 & 16 & 0 \\
\hline $\begin{array}{l}\text { For farmer operated devices, } \\
\text { pasture data collected rapidly } \\
\text { (e.g. 2-3 hours /100 ha) }\end{array}$ & 60 & 28 & 12 & 0 & 0 & 6 & 5 & 89 & 11 & 0 \\
\hline $\begin{array}{l}\text { Data from the measurement device } \\
\text { are in a format that can be uploaded } \\
\text { into third party software }\end{array}$ & 68 & 28 & 4 & 0 & 0 & 4 & 6 & 55 & 40 & 5 \\
\hline $\begin{array}{l}\text { For farmer operated devices, } \\
\text { the device is easy to maintain }\end{array}$ & 68 & 20 & 12 & 0 & 0 & 5 & 7 & 65 & 35 & 0 \\
\hline $\begin{array}{l}\text { Device has been calibrated in } \\
\text { ryegrass/clover swards }\end{array}$ & 60 & 24 & 12 & 0 & 4 & 8 & 8 & 68 & 32 & 0 \\
\hline \multicolumn{11}{|l|}{ 'NICE TO HAVE' } \\
\hline $\begin{array}{l}\text { The device has been calibrated } \\
\text { for different seasons }\end{array}$ & 56 & 20 & 8 & 12 & 4 & 9 & 9 & 37 & 53 & 11 \\
\hline $\begin{array}{l}\text { The device has been calibrated } \\
\text { in various New Zealand regions }\end{array}$ & 36 & 40 & 16 & 0 & 8 & 10 & 10 & 26 & 63 & 11 \\
\hline $\begin{array}{l}\text { For subscription-based services, } \\
\text { pasture data are delivered for } \\
\$ 2 / \text { ha or less per measurement }\end{array}$ & 17 & 35 & 13 & 4 & 30 & 12 & 11 & 32 & 68 & 0 \\
\hline $\begin{array}{l}\text { Device performance validated } \\
\text { by credible third party }\end{array}$ & 24 & 40 & 24 & 12 & 0 & 11 & 12 & 26 & 68 & 5 \\
\hline $\begin{array}{l}\text { Individual data points are } \\
\text { GPS tagged }\end{array}$ & 12 & 32 & 44 & 8 & 4 & 13 & 13 & 5 & 63 & 32 \\
\hline $\begin{array}{l}\text { The device has been calibrated } \\
\text { in non-ryegrass swards }\end{array}$ & 21 & 21 & 42 & 13 & 4 & 14 & 14 & 5 & 63 & 32 \\
\hline
\end{tabular}

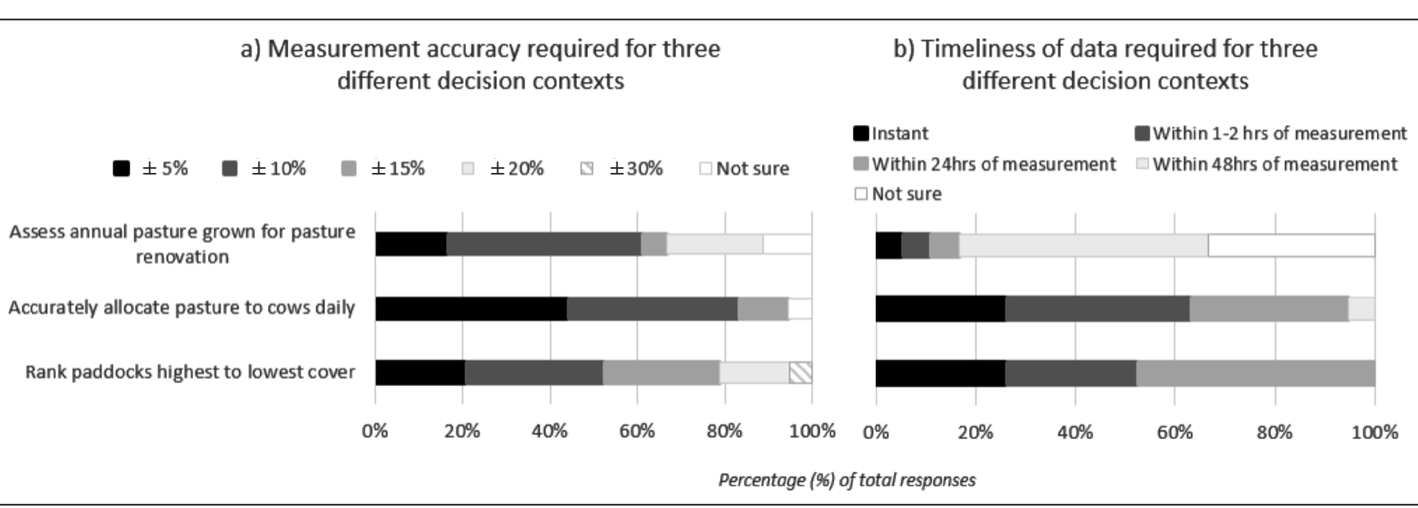

Figure 1 Minimum performance metrics for pasture measuring devices related to accuracy (a) and timeliness (b) attributes in three different grazing decision-making contexts.

2 was adapted based on respondent comments from Survey 1. For example, some respondents noted that requirements for pasture data would be dependent on the decision-making context, and on the time of year. Therefore, three decision making contexts (ranking paddocks, daily allocation of pasture, and identifying paddocks for pasture renewal) were included for questions regarding the accuracy and timeliness. The importance of measurement frequency in spring, summer, and winter was also added to Survey 2. Finally, in Survey 2, respondents chose the most appropriate 'minimum acceptable performance' a and timeliness of results in the three decision-making contexts (Figure 1) drawn from participant responses in Survey 1. Survey results were analysed using counts, means, and percentages.

\section{Results}

Primary attributes of pasture measuring devices

The results from the attribute rankings are provided in Table 1. In order of ranking, the eight most important attributes (where more than half of the respondents indicated the device 'needs to have') were: the device is easy to use (for farmer operated devices); pasture data are available weekly during high pasture growth periods; pasture data are available for farmers to use within 24 hours of measurement; pasture data are accurate (e.g. $\pm 200 \mathrm{~kg} \mathrm{DM} / \mathrm{ha}$ ); pasture data can be collected in 2-3 hours per 100 ha (for farmer operated devices); data are in a format easily uploaded into third party software; the device is easy to maintain (for farmer operated devices); and the device has been/can be calibrated for ryegrass/clover swards.

Minimum acceptable performance metrics related to pasture decision-making context The responses from participants are presented in
Figures 1 and 2. The main results are outlined below in respect to each of the three decision-making contexts.

1. Data needed to rank paddocks from highest to lowest pasture cover

From the options provided, most respondents $(79 \%)$ selected an accuracy level of $\pm 15 \%$ or better. Around half $(53 \%)$ selected a timeliness of $1-2$ hours for data availability after measurement, and all $(100 \%)$ said data should be available to farmers within 24 hours. For pasture measurement frequency, $65 \%$ said weekly for spring, $55 \%$ said weekly and $25 \%$ said fortnightly for summer, and $45 \%$ selected fortnightly followed by monthly (25\%) and weekly (20\%) for winter.

2. Data accuracy needed for daily allocation of pasture to cows

Most respondents (83\%) selected an accuracy level of $\pm 10 \%$, or better. Most $(63 \%)$ selected a timeliness of 2 hours after measurement, and almost all (95\%) said data should be available to farmers within 24 hours after measurement. For pasture measurement frequency, $37 \%$ said weekly in spring but a high proportion selected daily $(26 \%)$ and every 3-4 days (26\%). For summer, $47 \%$ said weekly, followed by daily (21\%) and every $3-4$ days $(16 \%)$, and for winter there was a wide range of responses, fortnightly (37\%) was the most popular followed by weekly (21\%) and monthly $(16 \%)$.

3. Data needed to assess annual pasture grown for pasture renewal

Most respondents $(61 \%)$ selected an accuracy level of $\pm 10 \%$ or better, however, there was more of a range compared with the other contexts with $22 \%$ indicating that $\pm 20 \%$ would be sufficient. In comparison with the other contexts, $17 \%$ selected a timeliness of 24 hours after measurement, with another $50 \%$ indicating data within 48 hours would be sufficient, 33\% answered 


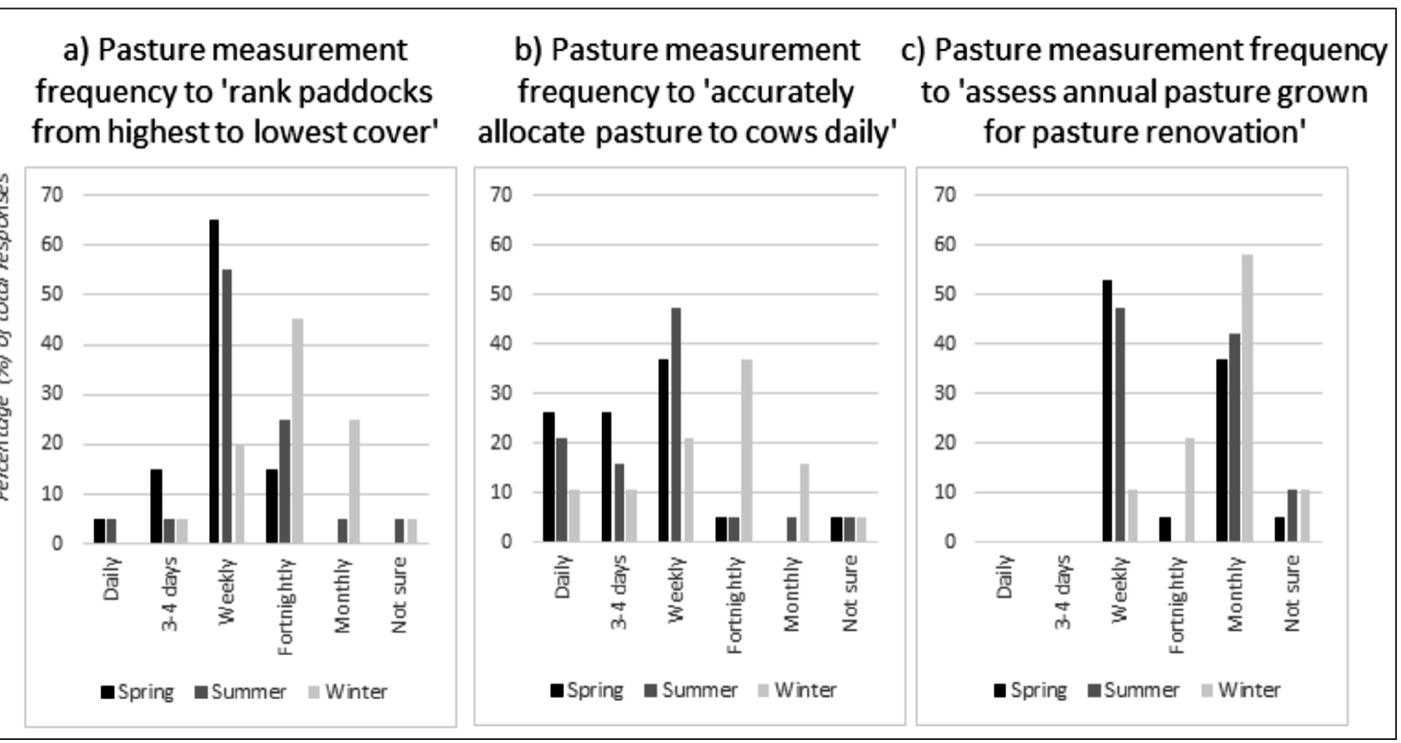

Figure 2 Minimum performance metrics for pasture measuring devices related to measurement frequency in three different grazing decision-making contexts ( $\mathrm{a}, \mathrm{b}$, and $\mathrm{c}$ ) in three periods of the year (spring, summer, and winter).

'not sure'. For pasture measurement frequency, 53\% said weekly in spring but a high proportion also selected monthly (37\%). For summer, $47 \%$ said weekly, and $42 \%$ said daily, and for winter $58 \%$ said monthly followed by fortnightly (21\%).

\section{Feedback from respondents}

Feedback included comments on calibration, some respondents noted that it would be costly to calibrate devices for different regions and other plant species, and suggested some form of self-calibration or farmer calibration method. Others suggested that more comprehensive calibration was needed to accoun for regional differences, and factors such as irrigated compared with dryland farming. Potential on-farm calibration would depend on the output from the device e.g. dry matter could be easy to calibrate, whereas pasture quality aspects would be harder for a farmer to analyse. A greater need for regional calibrations was identified by the Australian respondents. Some respondents noted that precision (repeatability) could be more importan than accuracy, and that accuracy requirements were closely linked to the intended use of the data. Use of a 'credible third party' to assess device accuracy was generally not considered worthwhile by respondents, due to it not being cost effective, but having some form of industry performance benchmark for measurement tools was suggested. One respondent suggested that companies developing devices should provide open access to their calibration data and algorithms.

Ease of use was identified as important, as well as ease of maintenance. Simplicity was key, according to one respondent. Some commented that farmers should accept some time investment for skill development, and that if the output is valuable then farmers 'will work it out'. In this respect, cost was seen to be less relevant as it depended on the benefit or perceived value by farmers, and that the market would determine this. Other general factors to consider were the level of back-up service and training, transportability of devices, total size of the market versus costs of development, and displaying the data in a form that helps users make management decisions.

\section{Discussion}

This study focussed on identifying attributes for pasture measuring devices for use in New Zealand dairy farming. The result provides guidance on the attributes that are 'nice to have' versus 'need to have'; for example, while calibration in ryegrass/clover swards was important for devices, seasonal and regional calibrations were collectively viewed as not necessary. However, the importance of attributes such as calibration depends on the device and context, and respondents showed uncertainty around the appropriate level of calibration. Also, according to the rankings, accuracy of devices also, iccos importc important than frequency of measurement, therefore the implication for development of new measuring methods, such as satellite based services, is that the ability to collect data frequently (e.g. weekly) should be a key focus, aligning with findings of Dalley et al. (2009). This will be dependent on the device having an acceptable level of accuracy, as discussed below.
The attributes selected by the respondents were from a list supplied, potentially influencing or limiting their opinions. This list was tested in the pilot survey, and respondents were invited to suggest new attributes after Survey 1 . Some attributes were adjusted for Survey 2, but based on the feedback, addition of new attributes was not justified, suggesting that the original list adequately covered the important attributes for pasture measurement The aim of Delphi surveys is to provide measuren cont The in of Delphide (Linstone \& Turoff 1975). Some of the attribute rankings changed between the two surveys, for example the importance of accuracy and speed of data capture increased, while the ranking for ease of data upload decreased, indicating that the respondents had reflected on the feedback of the Delphi group. Ranking of the different attributes would be influenced by both the attribute descriptions and the context respondents were thinking of when answering the surveys, particularly for international participants. The introduction of three different decision-making contexts in Survey 2 facilitated exploration of the contexts. The results highlighted that each decision context could require different levels of frequency, timeliness, and accuracy. This indicates that while measuring devices should be fit for their end purpose, they could be primarily targeted at feed allocation (accurate and frequent) or pasture renewal decisions (moderately accurate and less frequent) and therefore different devices could be used for different purposes. Dalley et al. (2009) also identified differences in farm size, staff ability, and terrain as drivers for use of different devices. Farmers should, therefore, be aware of the fit between operational performance attributes and intended use.

While many Delphi surveys involve three stages, with the first being open questions, we decided to use a two-stage process to maintain participant engagement, successfully achieved with 25 and 20 participants responding to Survey 1 and 2, respectively, from a total cohort of 25. The pilot survey was used as a pseudo first-stage where the attribute wording was refined. For example, instead of a broad attribute stating, 'pasture data are accurate' the pilot feedback was to be more specific to ' $\pm 200 \mathrm{~kg} \mathrm{DM} / \mathrm{ha}$ '. This was then adapted to a percentage error (e.g. $\pm 15 \%$ ) to account for the impact on pre- and post-grazing pasture cover, based on respondent feedback in Survey 1. The worling of these statements may have influenced respondent rankings if a respondent felt they were too prescriptive. Additionally, there are potential interactions between the rankings that cannot be accounted for using this method. For example, if a respondent was told that a device had a low accuracy then would they rank frequency above accuracy? Using the Delphi method, it is assumed that respondents viewed each attribute as falling within acceptable performance boundaries. Alternative methods, such as conjoint or discrete choice analysis would need to be used to explore potential interactions between attributes.

Sending the survey primarily to researchers and technology developers may produce different rankings to those farmers would provide. Also, respondents potentially answered with the pasture management practices of their home country in mind Some coional differences were noted through the additiona omments provided by respondents, for example, a need for calibration in different areas of Australia. The results of this study should, therefore, be considered within these stated limitations. While results provide a guide to the important attributes, the ranking will vary depending on the user; for example, if the user is a consultant compared with a farm assistant the level of data required may differ, along with additional aspects such as geoloction and ease of upload to software. Whether the device is farmer-operated or delivered by a contractor will also influence the importance of attributes; for example, 'ease of use' and 'time to capture data' would not be relevant for a satellite-based service. Additionally, a contractor may be more willing to invest time in learning to use a device compared with a farmer.

Providing a more specific context for selected attributes in Survey 2 highlighted that device performance specifications may vary depending on the end use of the data. For example, if a farmer wanted to rank paddocks to determine where the cows will graze next then the respondents identified that rapic access (1-2 hours after measurement) to weekly data in spring/summer), with a medium level of accuracy $( \pm 15 \%)$ was preferable. In comparison, if the aim was to allocate pasture daily, the specifications were $\pm 10 \%$ and preferably within 2 hours of measurement. For this decision context, dat frequef was still expected to requer was (n) se that tools such as satellite-based pasture measurement may have an easier fit with a broad approach of ranking paddocks due to lower accuracy requirements, but that, according to respondents, data supply within 24 hours would be vital. For accurate pasture allocation, accessing data more often than once per week would either necessitate measurement methods with greater regularity, or additional measurements by farmers of the next 3-5 paddocks to be grazed. This form of grazing management was highlighted by Hirst et al. (2014) who found that farmers first recruited paddocks into a grazing plan, then shuffled the actual grazing sequence closer to the date of grazing based on daily observations. However, development of a device which operates at the highest accuracy specifications (i.e. \pm 
$10 \%$ for allocation decisions), and still performed well in terms of other important attributes such as data collection speed, would still be the most useful to farmers as they could use the same device for dat across all decision contexts.

\section{Conclusions}

This study provides a first attempt at explicitly defining the important attributes for pasture measurement devices. It provides a guide to the attributes to consider, and some operational performance metrics, for the development of these devices and systems. We engaged with specialists in Australia and Ireland, as well a New Zealand, and while the research was targeted a New Zealand situations, the results can be adapted for guiding technology development and use in other pasture-based dairy systems internationally. Pasture data needs of different end users, such as multi-farm businesses, owner-operators, farm staff, and farm consultants are still to be determined.

\section{ACKNOWLEDGEMENTS}

This study was funded by New Zealand dairy farmer through DairyNZ Inc. in partnership with the Ministry of Primary Industries Primary Growth Partnership funding. The authors sincerely thank the experts who took part in the surveys.

\section{REFERENCES}

Dalley, D.; Clark, D.; Pairman, D.; Dynes, R.; Yule, I, King, W.; Mata, G. 2009. Technologies for measuring grass/crops. pp. 134-151. In: Proceedings of the South Island Dairy Event. Lincoln, New Zealand.

Dela Rue, B.T.; Eastwood, C.R. 2017. Individualised feeding of concentrate supplement in pasture-based dairy systems: practices and perceptions of New Zealand dairy farmers and their advisors. Animal Production Science 57: 1543-1549.

Eastwood, C.R.; Dela Rue, B.T.; Gray, D.I. 2017. Using a 'network of practice' approach to match grazing decision-support system design with farmer practice. Animal Production Science 57: 1536-1542.

Eastwood, C.R.; Jago, J.G.; Edwards, J.P.; Burke, J.K. 2016. Getting the most out of advanced farm management technologies: roles of technology suppliers and dairy industry organisations in supporting precision dairy farmers. Animal Production Science 56: 1752-1760.

Eastwood, C.R.; Kenny, S. 2009. Art or science? Heuristic versus data driven grazing management on dairy farms. Extension Farming Systems Journal 5: 95-102.

Edwards, J.P.; Dela Rue, B.T.; Jago, J.G. 2015. Evaluating rates of technology adoption and milking practices on New Zealand dairy farms. Animal Production Science 55: 702-709.

Hasson, F.; Keeney, S. 2011. Enhancing rigour in the Delphi technique research. Technological Forecasting and Social Change 78: 1695-1704.

Hirst, C.; Donaghy, D.; Gray, D.; Wood, B.; McCarthy, S. 2014. Exploring operational management used by dairy farmers to manage grazing. pp. 62-64. In: Proceedings of the 5th Australasian Dairy Science Symposium. Hamilton, New Zealand.

King, W.M.; Rennie, G.M.; Dalley, D.E.; Dynes, R.A.; Upsdell, M.P. 2010. Pasture Mass Estimation by the C-DAX Pasture Meter: Regional Calibrations for New Zealand. pp. 233-238. In: Proceedings of the 4th Australasian Dairy Science Symposium 2010. Lincoln, New Zealand. Caxton Press, Christchurch.

Linstone, H.A.; Turoff, M. 1975. The Delphi method : techniques and applications. Addison-Wesley Pub. Co. Advanced Book Program, Reading, Mass.

McCarthy, S.; Hirst, C.; Donaghy, D.; Gray, D.; Wood, B. 2014. Opportunities to improve grazing management. Proceedings of the New Zealand Grassland Association 76: 75-80.

Pullanagari, R.R.; Yule, I.J.; Tuohy, M.; Dynes, R.; King, W. 2011. Pasture quality measurement tools for decision making. In: Adding to the knowledge base for the nutrient manager. Occasional Report No. 24. Eds. Currie, L.D.; Christensen, C.L. Fertilizer and Lime Research Centre, Massey University, Palmerston North, New Zealand.

Thomson, N.A.; Upsdell, M.P.; Hooper, R.; Henderson, H.V.; Blackwell, M.B.; McCallum, D.A.; Hainsworth, R.J.; Macdonald, K.A.; Wildermoth, D.D.; Bishop Hurley, G.J.; Penno, J.W. 2001. Development and evaluation of a standardised means for estimating herbage mass of dairy pastures using the rising plate meter. Proceedings of the New Zealand Grassland Association 63: 149-157.

\section{Optical sensors for variable rate nitrogen application in dairy pastures}

K. WIGLEY ${ }^{1}$, J.L. OWENS ${ }^{2}$, J.A.K. TRETHEWAY ${ }^{3}$, D.C. EKANAYAKE ${ }^{1}$, R.L. ROTEN ${ }^{1}$ and A. WERNER ${ }^{1}$ Lincoln Agritech Ltd., PO Box 69133, Lincoln, Canterbury 7640, New Zealand ${ }^{2}$ Agriculture and Life Sciences Faculty, PO Box 84, Lincoln University 7647, Lincoln, New Zealand ${ }^{3}$ Syngenta Crop Protection, Private Bag 92618, Auckland, New Zealand kathryn.wigley@lincolnagritech.co.nz

Abstract

Reducing the amount of nitrogen $(\mathrm{N})$ fertiliser applied to dairy pastures down to agronomically optimised levels would have positive economic and environmental results. The ability of commercially available optical sensors to estimate biomass yield and foliar-N uptake in pastures was investigated. Vegetative indices (Simple Ratio, SR; Water Index, WI; and Normalised Difference Vegetation Index, NDVI) from two active optical reflectance sensors (N-Sensor, Yara; and Greenseeker, Trimble) were compared with manually measured biomass and $\mathrm{N}$-uptake in above-ground foliage. There were three measurements over time, from pastures that had received different $\mathrm{N}$ fertiliser applications rates $(0$, $10,20,40$ and $80 \mathrm{~kg} \mathrm{~N} / \mathrm{ha}$ ). It was found that the sensors were able to detect differences in biomass and foliar $\mathrm{N}$-uptake following defoliation of grazed pastures. The tested opticat sensors have the potential to inform a real-time variable rate fertiliser application system.

Keywords: pasture, nitrogen, optical sensors

\section{Introduction}

Modern intensive dairy farms inherently have low nitrogen use efficiency (NUE) (Powell et al. 2010). Lower N-fertiliser application to pastures at a comparable yield level would provide economic benefits to farmers who could spend less money on fertiliser. It could also benefit the environment by reducing the potential for nitrate leaching and nitrous oxide emissions (Maharjan et al. 2014). To reduce $\mathrm{N}$-fertiliser application and to determine the optimal rate of $\mathrm{N}$ required for different dairy pastures, strategies to quickly measure dry matter (DM) yields and pasture N-uptake are needed. One way to do this is by using optical sensors to infer vegetation indices such as NDVI, SR, and WI, which are calculated from reflectance values, and have been successfully related to plant yields and foliar N (Pullanagari et al. 2011; Roberts et al. 2015). By using optical sensors to detect areas of high $\mathrm{N}$ in pastures, such as areas with a large number of urine patches (Haynes \& Williams 1993; Jarvis et al. 1995), a variable rate system could avoid further fertiliser application to those areas, thereby improving NUE. Commercial optical sensors for efficient application of $\mathrm{N}$-fertiliser have been developed for intensive arable farming (Bragagnolo et al. 2013; Portz et al. 2012), but no such sensors have been developed for dairy pastures. The objective of this study was to test the performance of various vegetation indices (NDVI, WI, SR) measured from optical reflectance sensors to estimate biomass yield and $\mathrm{N}$-uptake in an irrigated dairy pasture.

\section{Methods}

The experiment took place at Lincoln University' Ashley Dene Research and Development Station $\left(43^{\circ} 38^{\prime} 42.0^{\prime \prime} \mathrm{S}, 172^{\circ} 20^{\prime} 33.0^{\prime \prime} \mathrm{E}\right)$ in Canterbury, New Zealand. The experiment was established on a stony, well-drained silty loam Balmoral Acidic Orthic Brown Soil (Hewitt 2010), with increasing stony sandy gravels beyond $15 \mathrm{~cm}$ depth. The newly established yearold past rennial ryegras Lolium perenne ), mixed with Italian ryegrass (Lolium multiflorum ), plantain (Plantago lanceolata) and white clover (Trifolium repens). Before establishment of thi pasture, the site was unirrigated and sheep-grazed.

The experimental area was subdivided into sixteen $12 \times 35 \mathrm{~m}$ plots. On the 11 October 2016, before the experiment started, the pasture was grazed by dairy cows. Following grazing, on 13 October 2016, urea certiliser was aplied at five rates $(0,10,20,40$ and by hand. Each fertiliser tratment was replicated three times in a randomised block design. During the experiment, the area was irrigated using a centre-pivot irrigator, as required. The plots were grazed again by dairy cows on the 31 October 2016 before the first data collection.

Sward reflection measurements using the sensors and calculating the vegetation indices were completed three times: 1,2 and 3 weeks post-grazing on 7 Novere 5 November, and 22 November 2016, respectively. Manual biomass collection was completed within 2 days of the sensor measurements.

\section{Biomass harvesting}

Biomass was harvested from within each plot from five $0.5 \times 0.5 \mathrm{~m}$ quadrats located along the middle axis of each plot. At each harvest, plants from each quadra were cut using hand-shears to a height of $\sim 5 \mathrm{~cm}(\sim 1500$ 